\title{
NARRATIVA VISUAL PRODUCIDA POR MUJERES EN LATINOAMÉRICA: EL AUTOCÓMIC COMO ESPACIO DE CUESTIONAMIENTO Y DENUNCIA
}

\author{
Drawn and written by Latin American women: the autocomic as a \\ space of both questioning and denunciation
}

\section{RESUMEN}

La narrativa gráfica ha experimentado una explosividad sorprendente, lo que se evidencia tanto en la cantidad de nuevas publicaciones anuales como en la calidad y el alcance de sus propuestas discursivovisuales. En el caso particular de Latinoamérica, se ha gestado en la última década una producción que rescata, desde una vereda otra, el relato autobiográfico, ampliamente utilizado en clásicos del género como Hadashi no Gen, Maus y Persépolis. Asimismo, se visualizan temáticas, técnicas y entramados discursivos diferentes, a través de los cuales, en mi opinión, se construye una subjetividad textual y gráfica traspasada por la necesidad de aprehender la memoria individual en la experiencia cotidiana y, a partir de este ejercicio, (de)construirse como agente crítico del entramado social actual de nuestro continente. En este contexto, este artículo pretende indagar en el autocómic visual de tres autoras contemporáneas: Power Paola (Virus tropical, 2011), Agustina Guerrero (Diario de una volátil, 2015) y Marcela Trujillo (Ídolo, una historia casi real, 2017), a partir del análisis de los discursos que el yo-enunciador articula en torno a códigos culturales de orden patriarcal, lo que permite a las voces autorales revelar $-\mathrm{y}$ rebelarse - frente a dispositivos hegemónicos, desde una posición que cuestiona, incluso, el androcentrismo tradicional de la historieta.

Palabras claves: narrativa gráfica latinoamericana, escritura de mujeres, autobiografía, enunciación, autocómic.

\author{
UNIVERSUM \\ Revista de Humanidades y Ciencias Sociales

\section{CLAUDIA ANDRADE ECCHIO} \\ Dra. en Literatura chilena e \\ hispanoamericana, Universidad del \\ Desarrollo. Santiago, Chile. Correo \\ electrónico: c.andrade@udd.cl; \\ lalaithdolin@hotmail.com \\ Es integrante de La Otra LIJ, espacio \\ de producción de conocimiento y \\ de difusión de la literatura infantil y \\ juvenil, y de RING Latinoamérica, \\ red de investigadores de narrativa \\ gráfica.
}




\begin{abstract}
Graphic novels have become surprisingly popular. This is evidenced in the quality, quantity, and relevance of year-to-year publications, all of which develop interesting narrative and discursive proposals. In the case of Latin America, the production of the last decade has been focused on rescuing, promoting, and developing the autobiographical story genre. Going beyond staples such as Hadashi no Gen, Maus and Persepolis, the local production visualises a number of themes, techniques, and discursive frameworks. All of these contribute to the formation of a text and image-nurtured canvas, driven by the necessity to encapsulate the memory of the individual in an every-day context. This allows the critical (de)construction of the social framework of our continent. The present paper explores the world of autocomics by means of three contemporary authors: Power Paola (Virus tropical, 2011), Agustina Guerrero (Diario de una volátil, 2015) and Marcela Trujillo (Ídolo, una historia casi real, 2017). An analysis of the corpus will show how the stories' narrators-enunciators unveil — and rebel against — the informing patriarchal framework whose hegemony permeates both the narrated world and the traditional androcentrism of the comic-book industry as a whole.
\end{abstract}

Keywords: Latin American graphic novels, women's writing, autobiography, enunciation, autocomic.

\title{
EL YO-ENUNCIADOR Y YO-GRÁFICO EN LA NARRATIVA VISUAL AUTOBIOGRÁFICA
}

En su libro El espacio biográfico. Dilemas de subjetividad contemporánea (2002), la investigadora argentina Leonor Arfuch nos hace conscientes de tres aspectos que no debemos soslayar quienes abordamos las llamadas 'escrituras del yo'. Primero, que estas escrituras ponen en tensión la indagación del mundo privado - en tanto tiempo transcurrido y vivido por un sujeto concreto- y su relación con el nuevo espacio de lo social (33); en este sentido, se trata de un 'yo performativo', cuyo campo de acción no 
se ciñe meramente a un modo de expresión o de representación, sino a un procedimiento, es decir, a un conjunto de estrategias ficcionales a través de las cuales se auto-representa. Dirá Arfuch:

No tanto la 'verdad' de lo ocurrido sino su construcción narrativa, los modos de nombrar(se) en el relato, el vaivén de la vivencia o el recuerdo, el punto de la mirada, lo dejado en la sombra... en definitiva, qué historia (cuál de ellas) cuenta alguien de sí mismo o de otro yo (60).

No se trata, por tanto, solo del establecimiento del pacto autobiográfico propuesto por Phillipe Lejeune (1994), quien, junto con poner el acento en el contrato de lectura, sitúa en el nombre propio - compartido por el autor, el narrador y el protagonista del relato - la clave textual para distinguir el discurso autobiográfico de otros cercanos (como el de la biografía, el diario íntimo, la autoficción, entre otros $)^{1}$. En mi opinión, más bien estamos frente a una 'posición enunciativa' que cuestiona su propio ejercicio de autoconstrucción identitaria a través de un sujeto enunciador provisorio que, en su calidad de ser hablado y de hablar, a su vez, en otras voces, se manifiesta consciente de su descentramiento así como de la presencia de las voces ajenas en su discurso.

Segundo, que estas narrativas del yo surgen frente al fracaso de los sujetos colectivos (el pueblo, la clase, el partido, la revolución) y, sin embargo, en tanto relatos de experiencias, son "[...] expresión de una época, de un grupo, de una generación, de una clase, de una narrativa común de identidad" (79). Para Arfuch, el espacio biográfico, en su doble articulación entre el yo y el nosotros, nos presenta un desafío: el hallazgo de una voz autobiográfica en sus acentos colectivos (80) por medio de la cual haya una 'revalorización de la idea misma de minoría' en tanto diferenciación de la norma hegemónica, que desafía la posición centro a partir de un 'yo enunciativo periférico', el

1 La investigadora chilena Lorena Amaro (2009) afirma, respecto de la propuesta de Lejeune, que para este autor es posible diferenciar la autobiografía y la ficción a partir de "[...] la identidad del nombre compartido por el autor, el narrador y el protagonista de un relato. Lo que llama pacto autobiográfico es la afirmación de esa identidad en el texto, mediada por la lectura; esto es, que el lector, al ver que estas tres entidades comparten un nombre, puede afirmar con certeza que está leyendo una autobiografía" (53). 
que, siguiendo la propuesta de Nelson Osorio (1991), produce estrategias que cuestionan, ironizan y/o rechazan el campo simbólico de poder. En esta misma línea, Lorena Amaro (2009) propone que la autobiografía, en tanto género histórico, si bien comparte con las memorias el repaso de ciertos acontecimientos desde una óptica personal, introduce un nuevo elemento: “[...] la reflexión en torno al desarrollo de la propia personalidad, muy en sintonía con la importancia que la modernidad le comenzaba a atribuir al sujeto y su individualidad" (51). En este sentido, el llamado sujeto autobiográfico se construye sobre la base de estrategias enunciativas que, por un lado, aseguran una ilusión de verosimilitud básica para el establecimiento de un pacto de lectura de orden factual y, por otro, dan cuenta de la centralidad del espacio subjetivo en términos de escritura y voz.

Tercero, que en la medida que las formas del espacio biográfico cuentan una historia o experiencia de vida, están sujetas a los procedimientos compositivos propios de la narratividad y, por tanto, al eje de la temporalidad. En este contexto, la heteroglosia de la voz narrativa, el insoslayable dialogismo, los mecanismos lingüísticos de inscripción y despliegue del yo/nosotros, entre otros, configuran una identidad entendida como "un trayecto siempre abierto a la diferencia" (Arfuch 97), un acto de habla a través del cual no solo se comunica algo (en términos de compartir), sino que enuncia una ilusión de presencia siempre desplazada, diferida, que configura el quién del espacio biográfico.

En el caso de la narrativa gráfica, el investigador español Alfredo Guzmán (2017) distingue dos formas de autocómics: factual y ficcional. En ambos casos, esta forma discursiva permite, a través de la creación de un yográfico, la construcción de un discurso de identidad, pero con procedimientos disímiles. En los autocómics de orden factual, la enunciación se articula a partir de cuatro elementos: la identidad entre el personaje principal y el autor, la comprensión por parte del lector que está frente a una enunciación factual - por lo que es necesario que tenga una referencialidad discursiva sólida que se afirme para aclarar la veracidad de la obra-, la presencia de un narrador extra-homodiegético actorizado con focalización interna fija — es decir, un 
narrador que describe las acciones que realiza el personaje y que admite únicamente una voz narrativa centrada en una sola persona- - y una densidad referencial que concentre la mayor cantidad de información para autentificar a la persona y, con ello, el relato (234-237). Por su parte, los autocómics ficcionales no se respaldan en el pacto referencial y, aunque a veces se incluye al autor como personaje central, no busca persuadir al lector de la veracidad del relato:

La autofabulación en el cómic es un acto lúdico que no transita exclusivamente por la autorrepresentación, sino que tiene lugar también en la construcción de anécdotas y en las situaciones inverosímiles en las que se sitúa, en las que dar testimonio de la vida real deja de ser lo importante y se utilizan los recursos de la ficción para contar cualquier tipo de fantasía (329).

En el caso de los autocómics de ficción, la enunciación pone en juego otro tipo de mecanismos, entre los que destacan lo inverosímil (con variantes que van desde la invención de situaciones que hacen evidente la ficción hasta la elaboración de historias en las que lo real queda relegado solo al vínculo entre el autor y el yo-gráfico), lo biográfico (en los que se recurre a la autoficción en búsqueda de la memoria o del entendimiento del pasado) y lo especular (en el sentido que suele haber una intromisión del autor en la diégesis, en la que no es un personaje principal) (Guzmán 334-348).

En este sentido, y siguiendo lo propuesto por Arfuch, en la narrativa visual de corte autobiográfico — sea autocómic factual o de ficciónestamos frente a un yo que no solo se construye a través de procedimientos narratológicos (a los que habría que adicionar la representación gráfica de sí mismo), sino, principalmente, ante un tipo de enunciación que se articula a partir de un relato retrospectivo, finito en términos de proyecto escritural acotado y que, a la vez que resignifica el camino de vida a partir de instancias de auto-reconocimiento y de auto-ficción, dialoga con su entorno en tanto se identifica con una generación, una clase, una etnia, un sexo-género, etc.

Estas disquisiciones respecto de la construcción del yo autobiográfico en la narrativa visual —en su doble articulación enunciativa y gráfica- 
nos llevan, además, a preguntarnos por la perspectiva ideológica de quien codifica. Si seguimos a María Isabel Filinich (1998), para quien el sujeto de la enunciación se articula entre un enunciador, que codifica desde 'cierta perspectiva', y un enunciatario, que decodifica desde 'cierta inteligibilidad' (39-40), en la enunciación se conjugan dos procesos intersubjetivos —un yo que produce un discurso apela a un tú que lo interpreta-, en los que se fungen la heteroglosia y el dialogismo bakhtinianos con diversas formas de apelación y efectos de modalización ${ }^{2}$ que, desde Benveniste ${ }^{3}$, han permitido analizar el discurso como un conjunto de acciones subjetivizadas que operan en la liminaridad del lenguaje mismo.

El sujeto de la enunciación dispone de 'formas vacías' para expresar el yo-aquí-ahora (los deícticos) y de 'formas llenas' para manifestar una actitud ante lo dicho (los modalizadores), lo que colabora en la plasmación de un 'tono' que el enunciador adopta para producir los efectos deseados; dicha tonalidad permite, por un lado, identificar la base afectiva del acto comunicativo (Spang 391-393) y, por otro, plasmar una visión de mundo ${ }^{4}$. El sujeto de la enunciación, en consecuencia, realiza un acto performativo que conjuga decir, hacer y padecer, en cuanto la acción de enunciar implica una 'dimensión pasional', en la que se combinan la modalización con la modulación del discurso, las que "[...] centran el discurso no en la realización, en el cumplimiento de una acción, sino en una fase previa que potencializa la acción y predispone el imaginario" (Filinich 110).

Es, precisamente, en esta fase previa en donde se juega la dimensión ideológica del acto de enunciación. Bakhtin, en su análisis de los tonos de la novela ${ }^{5}$, distingue entre tonalidades monológicas y dialógicas: mientras las primeras apuntan a la univocidad y transmisión del mensaje, estrategia

\footnotetext{
2 Quien produce el discurso, además, puede elegir modalidades de enunciación a partir, por ejemplo, de la selección de verbos modales, tales como deber, poder, soler, querer, necesitar, tener, que expresan una actitud del sujeto ante la acción verbal (Álvarez, 2001; Filinich, 1998).

3 Cfr.: "La naturaleza de los nombres propios" y "La subjetividad en el lenguaje".

4 Cfr.: "El problema de los géneros discursivos" (Bakhtin, Estética de la creación verbal 248-293).

5 Cfr.: "De la prehistoria de la palabra en la novela" (Bakhtin, Problemas literarios y estéticos 469-512).
} 
de la hegemonía simbólica y cultural cuyo objetivo es el establecimiento de una verdad de carácter oficial e indiscutible, las segundas construyen la multivocidad y la pluritonalidad, estrategia que disputa con la oficialidad (en tanto centro) el estatuto de verdad inalienable de los mensajes que promueve a través de mecanismos de subversión y distanciamiento. A raíz de lo expuesto, se entiende que la instancia de la enunciación responde a una 'práctica discursiva situada' (Filinich 30), pues tanto el yo que enuncia como el tú al que apela están determinados por la sociedad y la cultura de la que participan y que, a la vez, construyen.

Tanto modulaciones como modalizaciones atingentes a la instancia de enunciación corresponden a elecciones determinadas por razones estratégicas de carácter apelativo-perlocutivo, pues, a la vez que apelan a un otro buscan producir un efecto en él. En el caso de la narrativa visual de carácter autobiográfico, el yo-enunciador se permea a través de los discursos que encarna el protagonista, perspectiva desde la cual se articula no solo la visión de mundo que se quiere relevar, sino, además, la postura ideológica que se desea plasmar. Ello se refuerza a partir de la construcción del yo-gráfico, el que se configura no solo a partir del pacto de lectura - sea de orden factual o ficcional-, sino también de la identificación entre quien lee y el yo autorepresentado en el cómic, que se erige como un mecanismo ideológico clave a partir del cual es posible develar cómo se refuerzan o cuestionan determinadas posiciones enunciativas, ello atendiendo a los elementos que se relevan o se invisibilizan, sea de manera explícita o implícita.

En virtud de lo discutido previamente, a continuación se propondrá un acercamiento preliminar a los autocómics de tres autoras latinoamericanas: la colombiana Power Paola (Virus tropical, 2011), la argentina Agustina Guerrero (Diario de una volátil, 2015) y la chilena Marcela "Maliki”" Trujillo (Ídolo. Una historia casi real, 2017), a partir del análisis de la construcción del yo-enunciativo-gráfico presente en sus trabajos gráficos, perspectivas enunciativas y visuales que, no solo se sitúan en una posición de denuncia ante aquellos códigos culturales de orden patriarcal, sino que, además, se erigen como un sujetos femeninos conscientes de su propia $-\mathrm{y}$ necesaria - urgencia 
por posicionarse, mostrarse y narrarse.

\section{VIRUS TROPICAL O LA CRÍTICA A LA CULTURA PATRIARCAL}

Virus Tropical ${ }^{6}$ de Power Paola puede describirse como un autocómic de formación, pues aborda la infancia y adolescencia de su protagonista, hija de un ex sacerdote y de una madre mística, cuyo viaje de Quito a Cali, a nivel simbólico, representa el recorrido desde el sometimiento a las normas de la sociedad patriarcal hacia la autoconsciencia y la rebeldía. Dado que se trata de una autoficción biográfica, el yo-gráfico va cambiando a medida que el personaje principal crece, lo que permite apreciar sus transformaciones físicas con el paso de los años. Asimismo, a través de las ilustraciones, es posible darse cuenta de la timidez de la protagonista, de qué le causa inquietud o rabia, y, en particular, cómo el corte de pelo — que va de dos chapes amarrados con cintas negras a un cabello suelto, largo y rapado en la nuca, que solo en algunas instancias es tomado en una cola_- evidencia el recorrido de la subordinación hacia la autoafirmación.

Lo más interesante de esta obra gráfica, en términos de reflexión en torno a la identidad femenina, es la presencia de un yo-enunciador que cuestiona abiertamente la construcción simbólica androcéntrica que legitima y naturaliza la subordinación de la mujer. La niña, incluso antes de nacer, es catalogada por un facultativo como un "virus tropical" (primera viñeta, imagen 1$)^{7}$, situación que, si bien se presenta con cierta jocosidad, muestra de manera concreta una mirada acerca de lo femenino como 'una enfermedad infecciosa', que desestabiliza la racionalidad y que altera la 'temperatura corporal', un 'algo extraño' que debe ser puesto en observación y, en caso de ser necesario, verse sometido a los dispositivos de control patriarcal,

\footnotetext{
6 Publicado en partes en Colombia (2009, 2010 y 2011) y después como libro completo en 2011 por Editorial Común, Argentina. En 2017 fue adaptado a formato fílmico, bajo la dirección de Santiago Caicedo, y ya ha cosechado varios premios, entre ellos, el de mejor película de animación y canción original en los Premios Macondo (2018).

7 Las imágenes de Virus Tropical se encuentran en el Anexo 1.
} 
representado aquí por las figuras masculinas (médicos y padre, en primera instancia; después compañeros de curso y parejas).

En otra escena (última viñeta, imagen 1) se grafica la violencia discursiva a la que están sometidas las mujeres, la vulneración de sus cuerpos e incluso de sus opciones de vida. La madre, en una camilla ginecológica, debe enfrentar las voces opinantes frente a su 'extraña condición' y, con posterioridad, cuando ya se confirma su embarazo y le cuenta al padre - que aúna en su figura, a lo menos, dos poderes simbólicos que han constreñido a las mujeres: lo masculino-centro y lo católico-norma-, este manifiesta "estoy seguro de que esta vez sí será hombrecito" (última viñeta, imagen 2), aludiendo a su propia necesidad de trascendencia y a un mandato implícito hacia su mujer, quien ya le ha dado dos mujeres, Claudia y Patricia. Sin embargo, la madre se rebela y, al momento de elegir el nombre para su hija, es ella quien impone su voluntad: "No, esta vez yo escojo el nombre, se va a llamar Paola" (última viñeta, imagen 3).

En términos de la construcción del yo-mujer y de la crítica al modelo androcéntrico, las imágenes más significativas son las que inician los episodios titulados "Adolescencia" e "Identidad" (imágenes 4 y 5, respectivamente), que se contraponen al yo-gráfico niña (imagen 6), porque se constata la transformación del personaje principal en una adolescente que desborda su feminidad en símbolos que discuten, precisamente, el modelo, por ejemplo, la centralidad del cuerpo femenino, la sangre negra de la menstruación, el diablillo y el angelito que representan tanto las contradicciones de la pubertad como el cuestionamiento frente a las imposiciones del mundo adulto, el jockey con el símbolo de la paz y los patines, el volcán de fondo en erupción, la embarcación aparentemente a la deriva, entre otros, los que apuntan a mostrar la experiencia caótica del paso de la infancia a la adolescencia, en particular para las mujeres, quienes tienden a ser vistas en esta etapa, desde la cultura androcéntrica, como sujetos explosivos y veleidosos, como cuerpos deseantes y deseados, y cuyas manifestaciones de descontrol, más que potenciadas, deben ser constreñidas.

Por su parte, las secuencias de Paola niña conversando con su padre en 
el baño (imagen 6) y las ilustraciones de Paola adolescente (imágenes 4 y 5) dan cuenta de una estrategia implícita de cuestionamiento al modelo patriarcal a partir de la elección del yo-gráfico así como de los discursos que articula el yoenunciador. Por un lado, se ve a la protagonista en una posición de inferioridad frente a la figura paterna (imagen 6), no obstante, el espacio físico en el que se da la conversación, el contenido onírico que molesta al padre y la sugerencia del concurso de dibujo para conocer al Santo Padre ponen en evidencia la crítica del yo-enunciador frente a los imperativos androcéntricos encarnados por el padre/sacerdote, quien intenta desviar la creatividad 'peligrosa' de la hija hacia algo que considera 'más productivo', alejándola del espacio del deseo. Por el otro lado, Paola es el centro de la ilustración porque es su figura, sangrante (imagen 4) y rebelde (imagen 5), y ya no su contraposición con el padre, quien emerge como sujeto autónomo que busca no solo su identidad sino su propia forma - ya no la de los demás — de ver, estar y padecer el mundo.

La transversalidad de este autocómic de formación no solo está en la historia de crecimiento de la niña a mujer, sino, en especial, en los imaginarios que evidencian y discuten por medio del yo-enunciador y el yo-gráfico, en particular en torno a la cultura patriarcal en el contexto latinoamericano. La escena final, que muestra a la protagonista de espaldas al lector, caminando por la calle con solo una mochila al hombro, es el inicio de lo que vendrá: "Sentía que desde hacía algún tiempo todo había ido llevándome a este punto, a prepararme para salir al mundo y hacer mi vida" (159). El 'virus tropical' que es Paola, pasados estos 'años de aprendizaje', camina al encuentro de su propia autonomía, ahora consciente de las dificultades que enfrentará por el solo hecho de ser mujer, pero como agente desestabilizador y de cambio, y no de replicación y perpetuación del modelo.

\section{DIARIO DE UNA VOLÁTIL O EL CUESTIONAMIENTO A LOS ESTEREOTIPOS FEMENINOS}

El diario ilustrado de Agustina Guerrero — cuyo origen es un blog del 
mismo nombre iniciado en 2011- se caracteriza por presentar una serie de entradas en los que un yo-enunciador registra su cotidianidad a través de un yo-gráfico multifacético, carismático y extraordinariamente voluble. Dichas entradas carecen de una orientación cronológica (no está fechado), por lo que, a ratos, más que un diario parece una serie de pensamientos ilustrados, algunos por medio de una imagen única, otros en secuencias, e incluso introduciendo unas tiras cómicas breves. La protagonista del diario es 'la volátil', una treintañera que viste siempre con una camiseta a rayas, y que es descrita en el paratexto de la contraportada como una mujer que "[s]abe lo que le gusta, quién es, y lo que ganó con la madurez: algunas partes del cuerpo más fofas, ipero también convicciones! [...] es sensible, un poco desprolija y muy efusiva" (Contraportada edición Sudamericana). Es interesante constatar que se haya utilizado el término 'volátil' —que se asocia con variabilidad e imprevisibilidad - para denominar al yo-gráfico y no un nombre propio. Hay aquí, en mi opinión, una elección consciente de mostrar este desbordamiento en el habla, en el cuerpo, en los pensamientos, en los actos, incluso en la multiplicidad de entradas, como una forma de discutir los discursos construidos desde la ideología patriarcal en torno a las mujeres (imágenes 1 y 2$)^{8}$.

Entre los discursos que han pretendido legitimar la subordinación de las mujeres se encuentra el de la inferioridad, que se relaciona con cualidades vistas como propias de los sujetos femeninos, por ejemplo, el infantilismo, la sensibilidad o la carencia de determinadas cualidades físicas, morales e, incluso, intelectuales. La volátil pareciera condensar, precisamente, en su figura desbordante, su gestualidad exacerbada y su habla explosiva, ese imaginario femenino de la mujer infantil, veleidosa y sensiblera; sin embargo, desde mi lectura, se trata más bien de procedimientos paródicos que ponen en juego el yo-enunciador, los que se manifiestan en la utilización de recursos hiperbólicos y carnavalescos propios del discurso dialógico descrito por Bakhtin (imágenes 3 y 4), los que, a través de la risa, desarticulan la construcción simbólica androcéntrica de la mujer llorona, cambiante e imposible de comprender desde

8 Las imágenes de Diario de una volátil se encuentran en el Anexo 2. 
la lógica masculina. El Diario juega todo el tiempo con este imaginario; de hecho, la pareja de la protagonista, cuando aparece, se le ve confundido frente a la volatilidad de su compañera, lo que demuestra con el ceño fruncido, las cejas enmarcadas en actitud dubitativa y los ojos levantados mirando el techo, siempre intentando no perder la paciencia con ella. En ello, justamente, hay una crítica encubierta a la mirada masculina condescendiente y que aparenta comprensión sin haberla: "A las mujeres hay que quererlas, no entenderlas" es la frase cliché que sintetiza la postura del hombre respecto de su mujer volátil.

Junto a lo anterior, uno de los aspectos centrales que discute este autocómic es la desarticulación del discurso-centro en torno al cuerpo 'perfecto' de las mujeres. La volátil se ríe de su propia corporalidad que no se ajusta a la norma patriarcal: su pelo tomado en tomate, su cara desgreñada en las mañanas, sus posturas mientras realiza labores domésticas, sus expresiones faciales. Todo en ella pone de manifiesto, a la vez que critica, las imposiciones de todo tipo a las que las mujeres se ven sometidas. Entre la multiplicidad de imágenes, destaco dos: en la primera se muestra una secuencia donde la protagonista se intenta colocar una panty media (imagen 5), mientras que en la segunda, se la muestra duchándose (imagen 6). Ambas instancias corresponden a momentos de la vida cotidiana - vestirse y bañarse - , no obstante, retratan, a nivel simbólico, por un lado, las dificultades de cumplir con parámetros de belleza física alejados de la realidad de las mujeres y la frustración que provoca el 'no calzar', y, por otro, el auto-placer femenino. En este sentido, el Diario, a través de un yo-gráfico desbordado y desbordante, cuestiona no solo el discurso de inferioridad, sino también el menosprecio frente a esta forma de ser mujer, que no está acorde a los ideales de mesura, pudor y silencio que, tradicionalmente, se les han exigido a los sujetos femeninos.

En este sentido, la volátil reivindica a este tipo de mujer que, desde la ideología patriarcal, es descrita como la histérica, la loca, la bulliciosa, y pone el acento en una interioridad y corporalidad femeninas que se exponen sin tapujos por medio de un diario íntimo, en el que la apuesta del yo-enunciador es, precisamente, dejar el espacio de lo privado asignado a la mujer para disputar el espacio público, lo que, en términos de escritura autobiográfica, 
podría reflejarse también en el cambio de formato y medio de difusión: desde el diario íntimo/papel al blog/digital.

\section{ÍDOLO O LA REIVINDICACIÓN DE LA MUJER EN EL CIRCUITO ANDROCÉNTRICO DEL CÓMIC}

La identidad femenina también se construye mediante los estereotipos de género sexual, los que son útiles para el orden de la sociedad patriarcal, en la medida que normalizan códigos de conductas que le asignan a la mujer el espacio privado y del hogar, el servicio doméstico y la crianza, mientras que permiten al hombre desplegarse en el espacio público. Estos roles de sexo-género son normados y aceptados por la sociedad, aprendidos e internalizados en la familia y la escuela, y sustentados por la religión y los medios de comunicación, entre otros aparatos ideológicos. En Ídolo. Una historia casi real de Marcela Trujillo, uno de los temas que atraviesa el relato gráfico es el posicionamiento de las ilustradoras en un espacio de poder que, tradicionalmente, ha estado bajo la esfera masculina.

La historia se enmarca en un viaje realizado por la protagonista a una Feria de Ilustración de Lima, en donde tiene la oportunidad de conocer a su 'ídolo', Rolf Runde, un famoso dibujante de origen noruego, con quien, efectivamente, tendrá un encuentro fortuito pero significativo (imágenes $1 \mathrm{y}$ $2)^{9}$. Sin embargo, el relato gráfico no se queda en solo la exposición de la anécdota personal: por un lado, y a través de la metaficción, introduce una trama paralela en donde personajes de sus cómics (Maliki cuatro ojos y el chanchito Kokoro) junto a dos santas peruanas (Santa Rosa de Lima y Sarita Colonia) nos sumergen en el centro del deseo de la protagonista por medio de una experiencia a la vez onírica, surrealista, neobarroca, en la que el cuerpo se torna central; por otro, en el desarrollo de las actividades características de una feria de este tipo, se nos muestra a otras ilustradoras (entre ellas, la misma Power Paola), quienes, a través de su participación en la charla "Mi cuerpo es

\footnotetext{
$9 \quad$ Las imágenes de Ídolo, una historia casi real se encuentran en el Anexo 3.
} 
mío, representaciones de cuerpos femeninos en el cómic hecho por mujeres", critican abiertamente la forma en que las mujeres han sido representadas por los hombres en el cómic (en particular, el de superhéroes) y plantean sus dificultades a la hora de abordar críticamente su propio ejercicio narrativovisual (imagen 3).

Por su parte, la relación entre el personaje principal y su ídolo permite al yo-enunciador abordar dos temas significativos: primero, la construcción de una masculinidad-otra, que se manifiesta en distintos momentos de la obra pero que, en particular, destaca en la escena en la que Marcela le confiesa a un amigo argentino que todos los hombres con los que ha estado se le han puesto a llorar en la cama (imagen 4); segundo, la denuncia pública frente a un acto de misoginia, abuso de poder y acoso laboral que la autora debió sufrir en su vida real, perpetuado por los editores de su primer libro (imagen 5). Esto último es relevante, en la medida que la ilustradora pasó años sin contar el episodio en el que participaron el comediante Rodrigo Salinas (quien, en esta obra, tiene apellido Salineros), Carlos Reyes y Rodrigo Dueñas, todos de Feroces Editores, a quienes no denunció en su momento porque, en palabras de la propia Maliki, "me dio miedo [...] [y] no quise meterme en un cacho" (El Desconcierto). En este contexto, el yo-enunciador deja en evidencia la importancia de hablar de la experiencia traumática, no solo como un mecanismo de liberación personal sino, principalmente, como un 'ya no más' al ninguneo y al abuso de poder de la sociedad patriarcal, consigna que movimientos como \#MeToo o las marchas feministas en todo el mundo han hecho carne y que manifiesta, más que una rabia contenida, un grito de 'no vamos a callar nunca más'.

El yo-enunciador de este autocómic no se queda solo en la denuncia frente a la violencia de género o los micromachismos que experimentan las mujeres en el ámbito de la ilustración y la historieta, sino que, además, manifiesta la importancia de la sororidad en espacios donde la cultura patriarcal —entendida aquí como forma de depredación — intenta tanto invisibilizar el trabajo realizado por mujeres como perpetuar un estereotipo físico específico sobre cómo deben ser representadas en la narrativa gráfica. La protagonista lo enuncia con claridad en la charla sobre las representaciones del cuerpo 
femenino en el cómic: "Lo que yo veo es que las mujeres no sólo nos retratamos físicamente, sino que retratamos la idea que tenemos de nosotras... y muchas veces esa idea es todo menos pasiva, sumisa, sensible o un mero complemento para satisfacer al hombre" (244). Aquí, justamente, se haya el centro de la crítica expuesta a través de esta novela gráfica y el hecho de destinar varias viñetas a la charla misma da cuenta de la urgencia de hablar de estos temas, de darle voz a las mujeres que escriben e ilustran cómics, a sus aspiraciones e inquietudes, a sus luchas y a las vicisitudes que deben sortear.

\section{A MODO DE CIERRE}

Los estudios sobre las operaciones e implicaciones ideológicas de los discursos ${ }^{10}$ han puesto en evidencia que la interacción entre autor, texto y lector no se construye sobre un espacio vacío, sino que se produce y es recibida por sujetos traspasados por posicionamientos ideológicos, políticos, económicos, sociales y culturales que, explícita o implícitamente, están presentes en la comunicación en general. A raíz de ello, se hace necesario abordar, desde las propuestas teóricas en torno a la instancia de enunciación, la construcción del yo-enunciador en la narrativa gráfica de corte autobiográfico, en la medida que, junto con presentarnos un yo-gráfico, colabora en la transmisión, discusión y subversión de discursos sociales y culturales vigentes o no en un momento histórico determinado.

En tanto práctica situada, estas narrativas visuales se inscriben en un contexto latinoamericano donde, por un lado, las autoras luchan por posicionar sus formas de representación de la realidad, de contar historias e ilustrarlas, en un espacio que, tradicionalmente, ha estado traspasado por la mirada $-\mathrm{y}$ el ejercicio - de los hombres; por otro, a partir de estrategias que buscan poner en evidencia las prácticas patriarcales, las autoras han construido yo-gráficos

\footnotetext{
10 Cfr.: Van Dijk, "Política, ideología y discurso" (2005); Žižek, "Introducción. El espectro de la ideología" (2003); Thompson, Ideology and Modern Culture. Critical Social Theory in the Era of Mass Communication (1990); Mannheim, Ideología y utopía. Introducción a la sociología del conocimiento (1987).
} 
femeninos que cuestionan la cultura androcéntrica en términos de corporalidad y estereotipos, y han articulado discursos de crítica a dicho modelo por medio de un yo-enunciador que se posiciona desde el develamiento de "malas prácticas' y el activismo.

Retomando el inicio de este artículo, la liminaridad propia de la enunciación, la dimensión ideológica que se permea a través de ella, la identificación como estrategia apelativo-perlocutiva, la denuncia desde este yo-periférico construido textual y visualmente en el autocómic, la presencia del yo/nosotros/otros propio del espacio biográfico, hacen de la narrativa gráfica de corte autobiográfico una instancia única para que las ilustradoras posicionen temas como la descosificación del cuerpo femenino, el empoderamiento de las mujeres y la discusión de los estereotipos de género-sexual, desde una práctica conscientemente contestataria y performativa.

\section{BIBLIOGRAFÍA}

Álvarez, Gerardo. “El texto y su enunciación”. Textos y discursos. Concepción: Universidad de Concepción, 2001. 25-57. Impreso.

Amaro, Lorena. Vida y escritura. Teoría y práctica de la autobiografía. Santiago: Ediciones Universidad Católica de Chile, 2009. Impreso.

Arfuch, Leonor. Elespacio biográfico. Dilemas desubjetividad contemporánea. Buenos Aires: FCE, 2010. Impreso.

Bakhtin, Mikhail. Estética de la creación verbal. Trad. Tatiana Bubnova. Madrid: Siglo XXI, 1990. Impreso.

_. Problemas estéticos y literarios. Trad. Alfredo Caballero. La Habana: Arte y Literatura, 1986. Impreso.

Benveniste, Emile. "La naturaleza de los pronombres" y "De la subjetividad en el lenguaje". Problemas de Lingüistica General I. México D.F.: Siglo XXI, 1997. 172-187. Impreso.

Filinich, María Isabel. Enunciación. Buenos Aires: Eudeba, 1998. Impreso.

Guerrero, Agustina. Diario de una volátil. Buenos Aires: Sudamericana, 2015. Impreso. 
Guzmán, Alfredo. "Autocómics factuales". Figuraciones del yo en el cómic contemporáneo. Tesis de Doctorado, Universidad Autónoma de Barcelona, 2017. 227-319. Web. 26 feb. 2019.

https://ddd.uab.cat/pub/tesis/2017/hdl_10803_456586/acgt1de2.pdf

Lejeune, Philippe. El pacto autobiográfico y otros estudios. Trad. Ana Torrent. Madrid: Megazul-Endymion, 1994. Impreso.

El Desconcierto. "Marcela "Maliki" Trujillo y su episodio de abuso de poder: "No pude hacer la denuncia legal porque me dio miedo". Entrevista dada el 22/11/2017. Web. 19 mar. 2019. https://www.eldesconcierto. cl/2017/11/22/marcela-maliki-trujillo-y-su-episodio-de-abuso-sexualcon-un-editor-no-pude-hacer-la-denuncia-legal-porque-me-diomiedo/

Osorio, Nelson. "Ficción de oralidad y cultura de la periferia en la narrativa mexicana e hispanoamericana actual". Literatura mexicana hoy. Del 68 al ocaso de la revolución. Ed. Karl Kohut. Alemania: Vervuert Verlag, 1991. 243-252. Impreso.

Power Paola. Virus Tropical. Buenos Aires: La Editorial Común, 2011. Impreso.

Spang, Kurt. "Acerca de los tonos en la literatura". Revista de Literatura LXVIII. 136 (jul.-dic. 2006): 387-404. Web. 26 feb. 2019.

http://revistadeliteratura.revistas.csic.es/index.php/revistadeliteratura/article/ viewFile/13/15\&a=bi\&pagenumber $=1 \& w=100$

Trujillo, Marcela. Ídolo. Una historia casi real. Santiago: Penguin Random House, 2017. 


\section{ANEXO 1: IMÁGENES VIRUS TROPICAL DE POWER PAOLA}

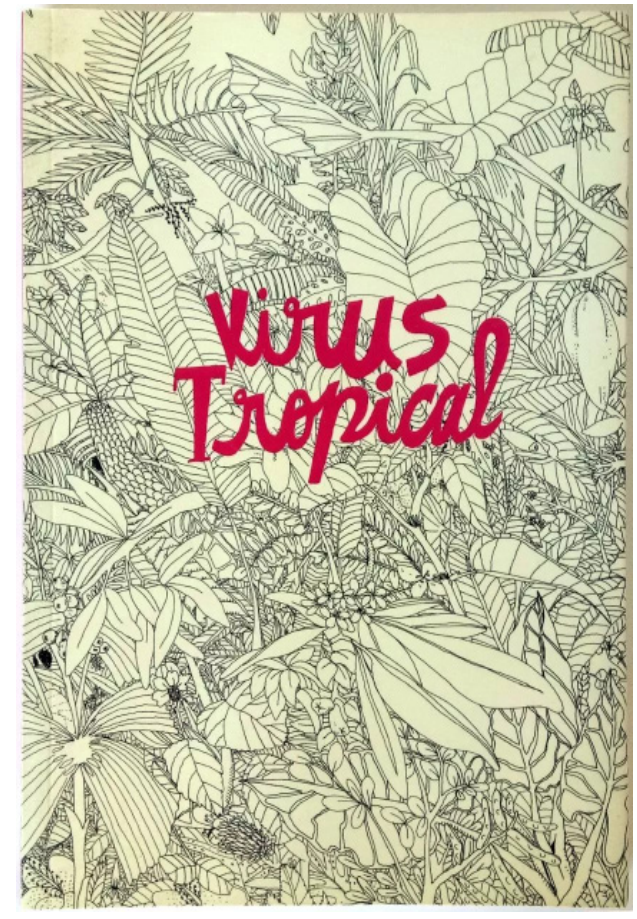

Portada Virus Tropical

Editorial Común, Argentina (2014).

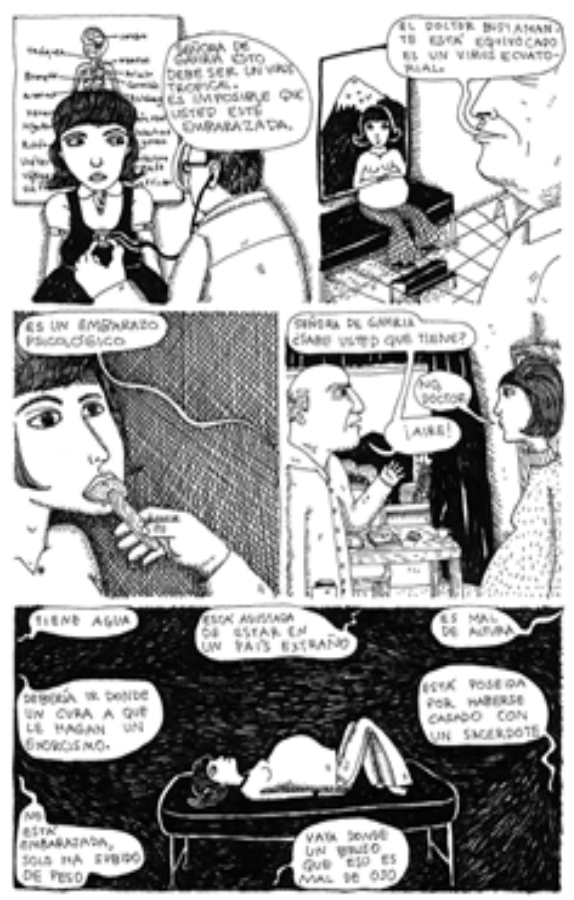

Imagen 1 


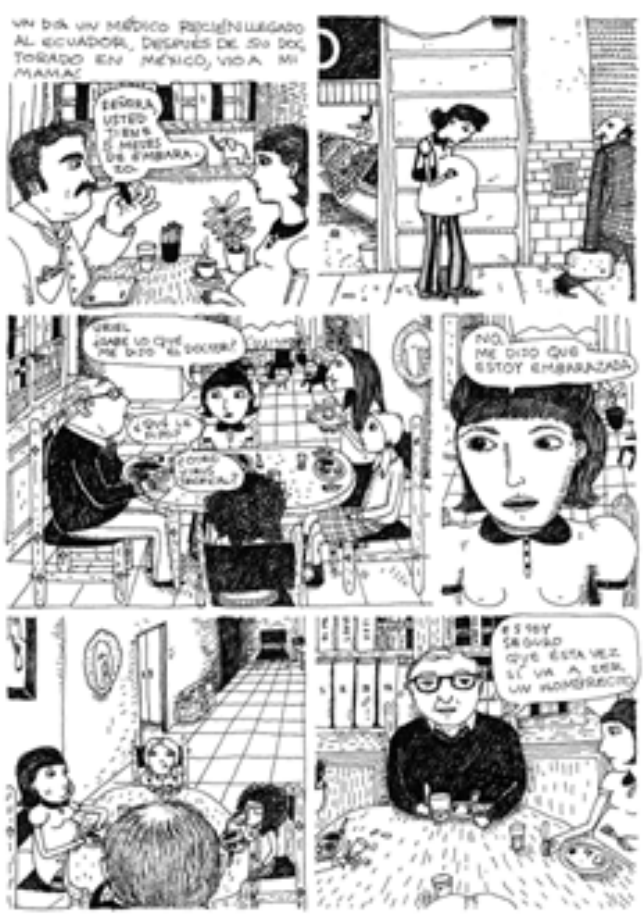

Imagen 2

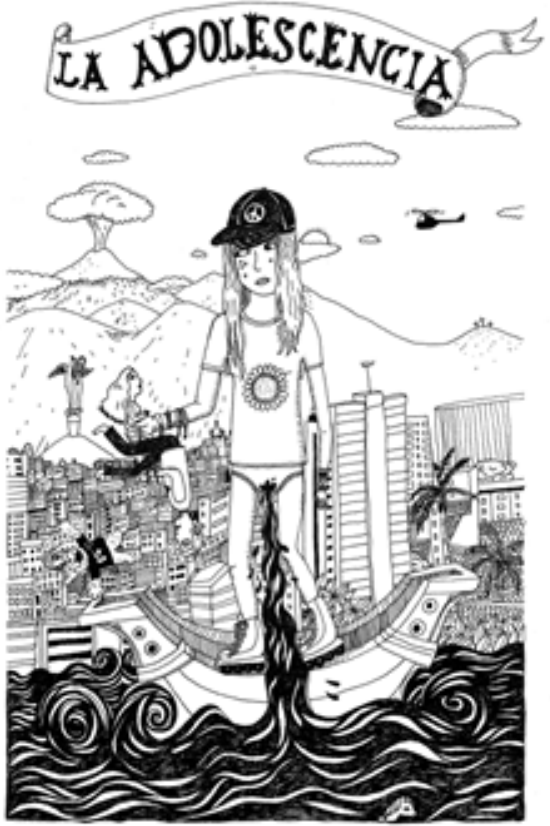

Imagen 4

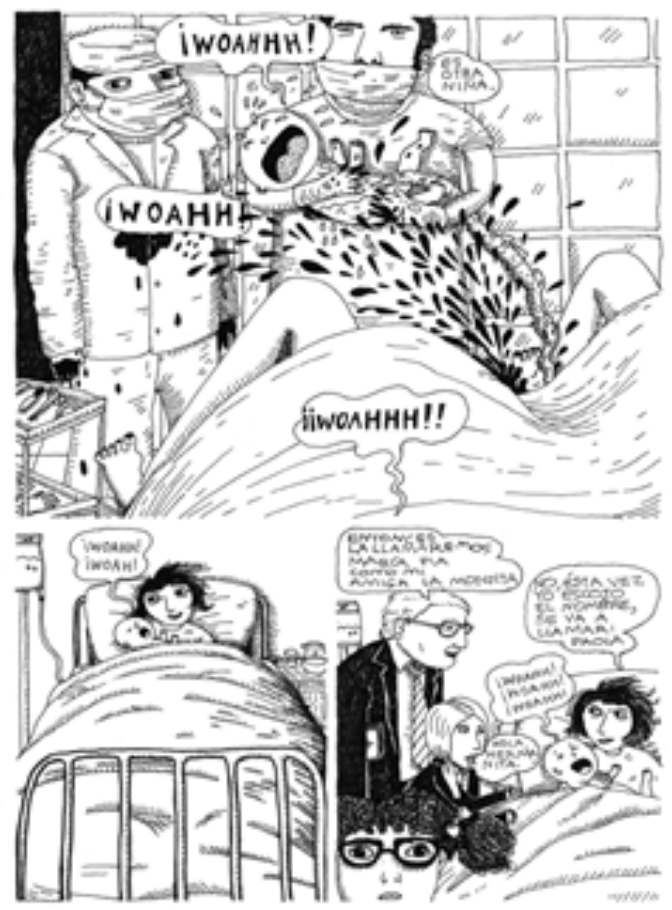

Imagen 3

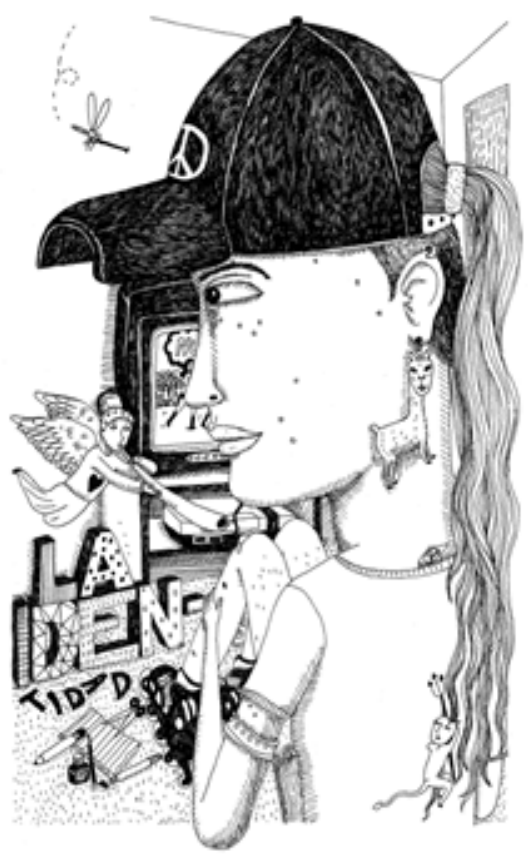

Imagen 5 


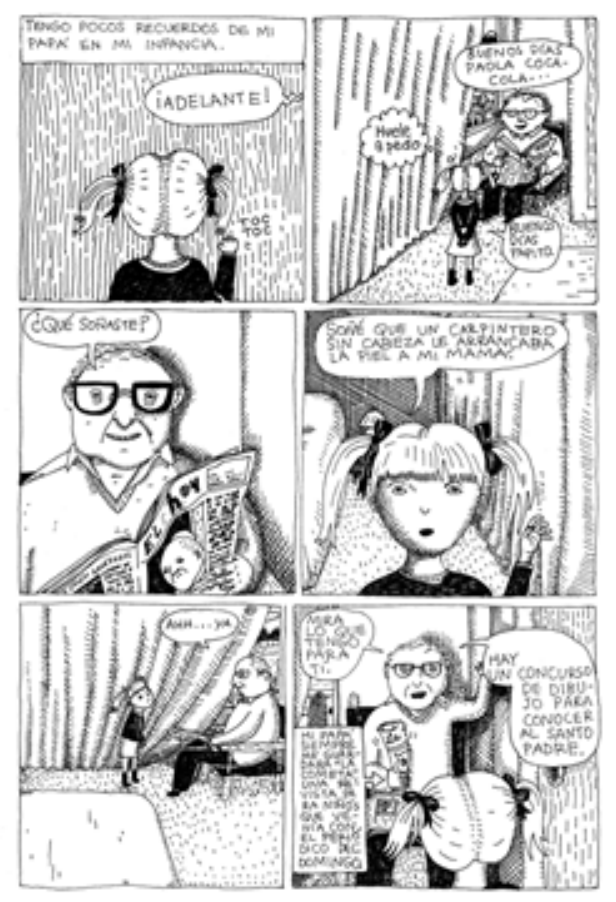

Imagen 6 


\section{ANEXO 2: IMÁGENES DIARIO DE UNA VOLÁTIL DE AGUSTINA GUERRERO}

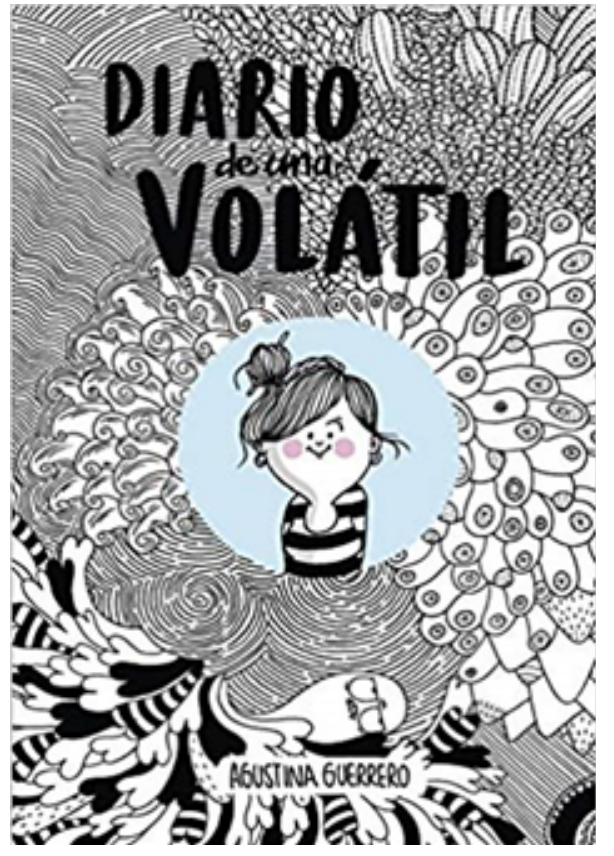

Portada Diario de una volátil Editorial Sudamericana, Argentina (2015)

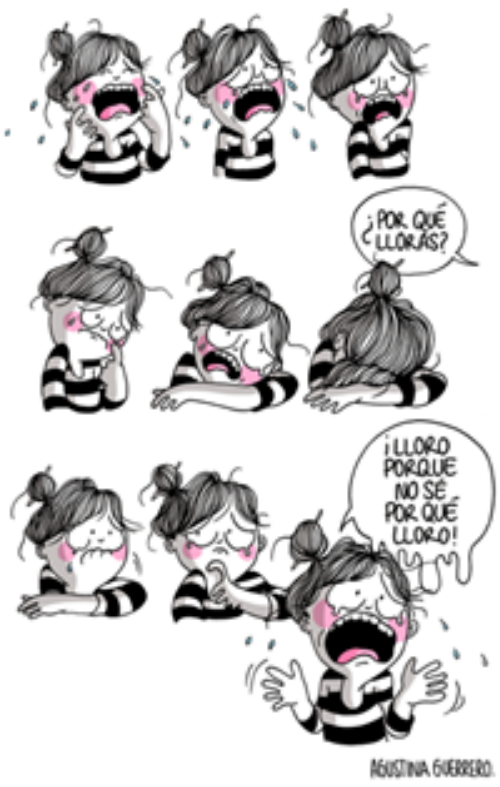

Imagen 2

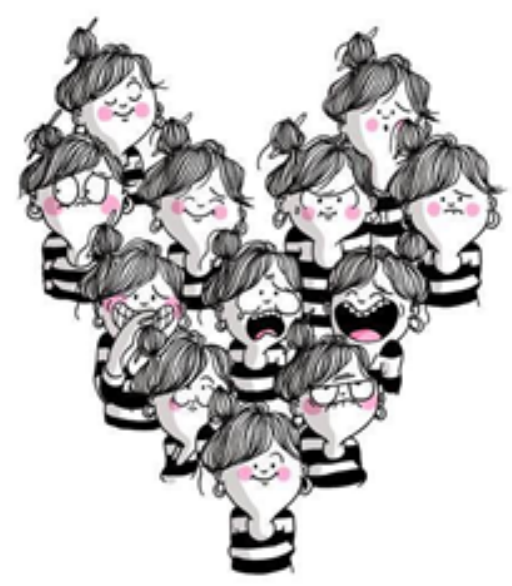

SEREMOS LO QUE SEREMOS. PERO ¡QUÉ BUENO ES SER MUJER! AGUSTNA GUEOESPO

Imagen 1

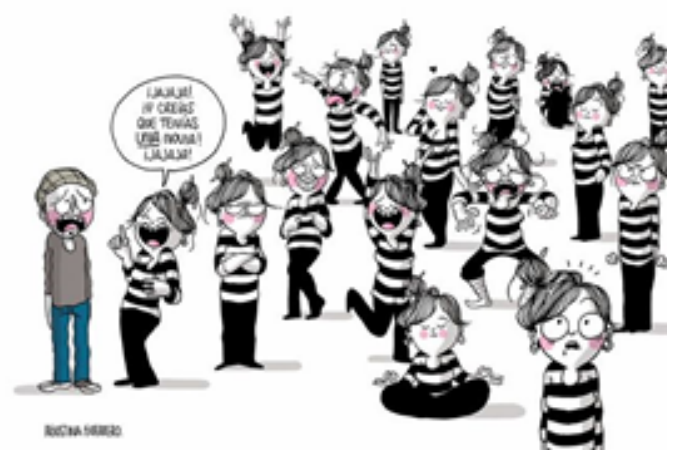

Imagen 3 


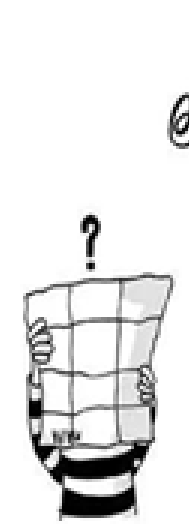

ole Shonfiass

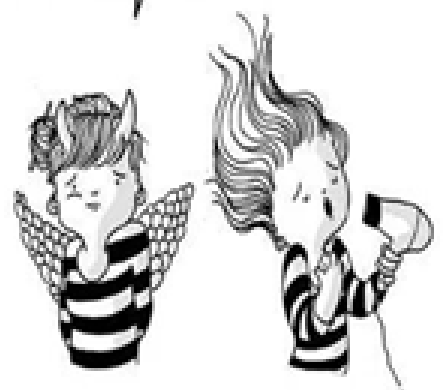

NOT TEGO BEA

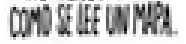

If SODO IIfA

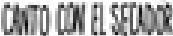
YKE HWO USRR.

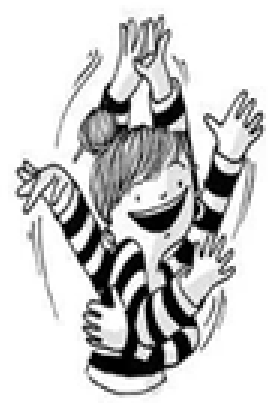

regonalis

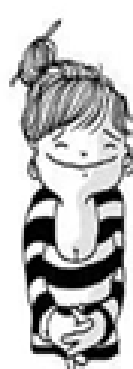

ronotions

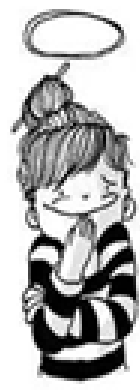

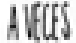

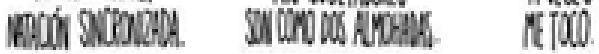

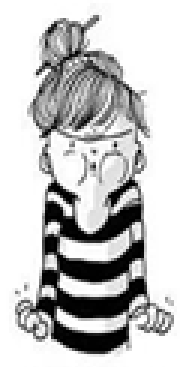

WWH IS POWO SBR

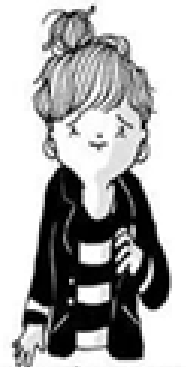

rourrougarde.

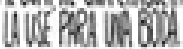
y u onoli.

Imagen 4

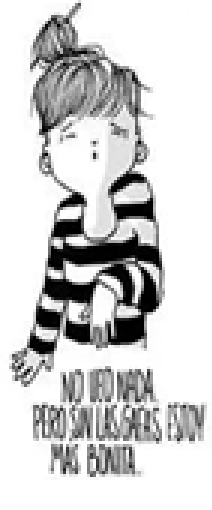

(wentine)

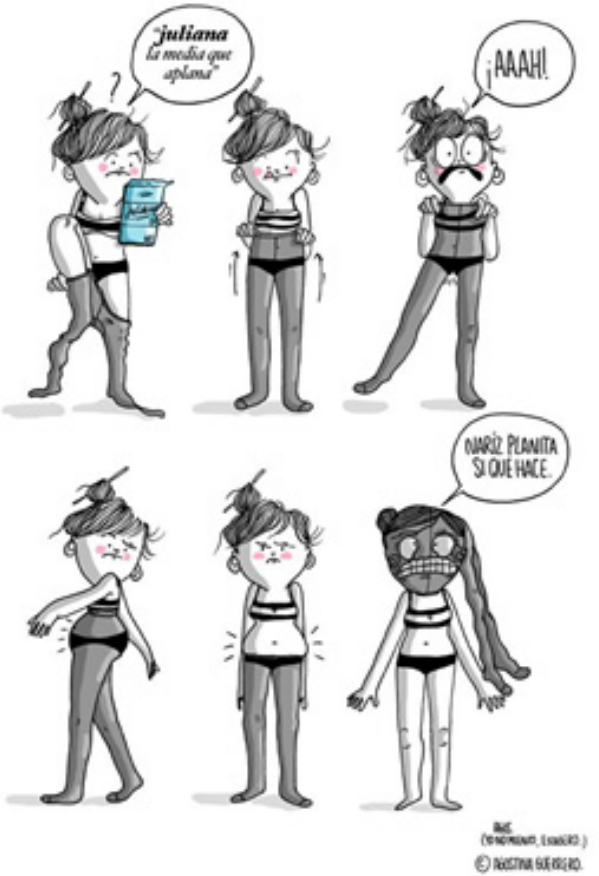

Imagen 5

DUCHITA (MUY) RELAJANTE

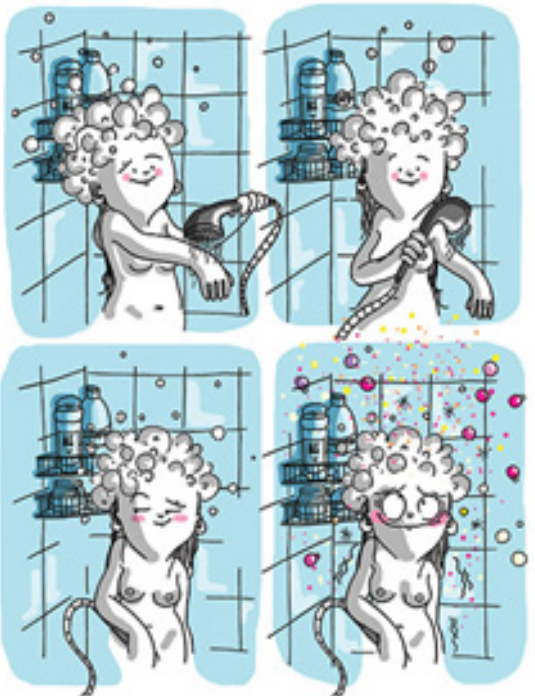

Imagen 6 


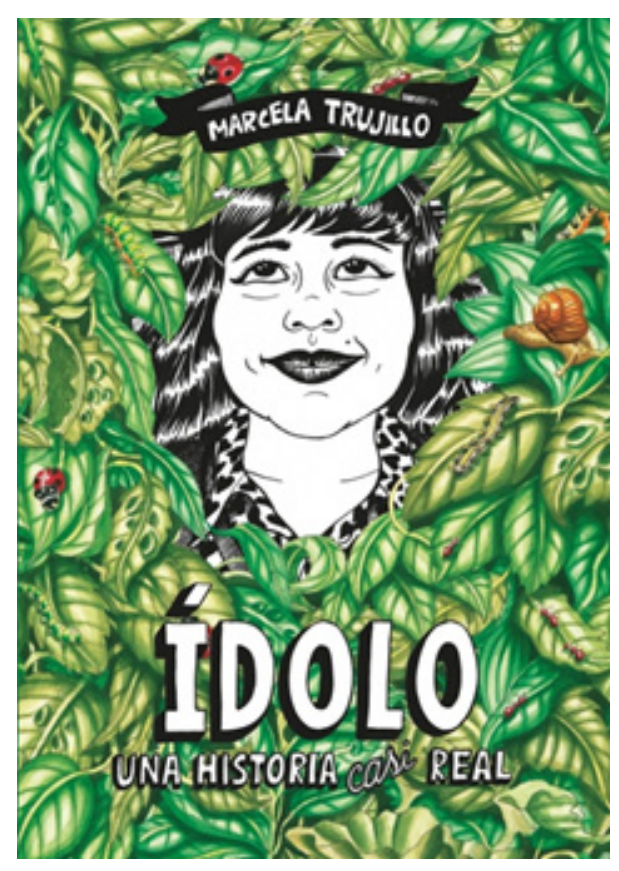

Portada Ídolo. Una historia casi real Editorial Penguin Random House, Chile (2017).

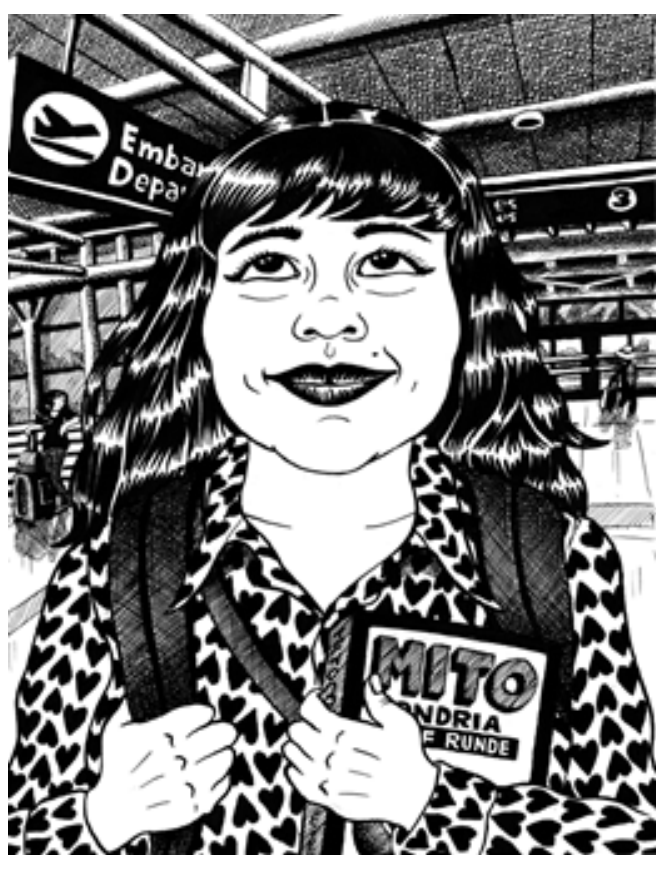

Imagen 1 

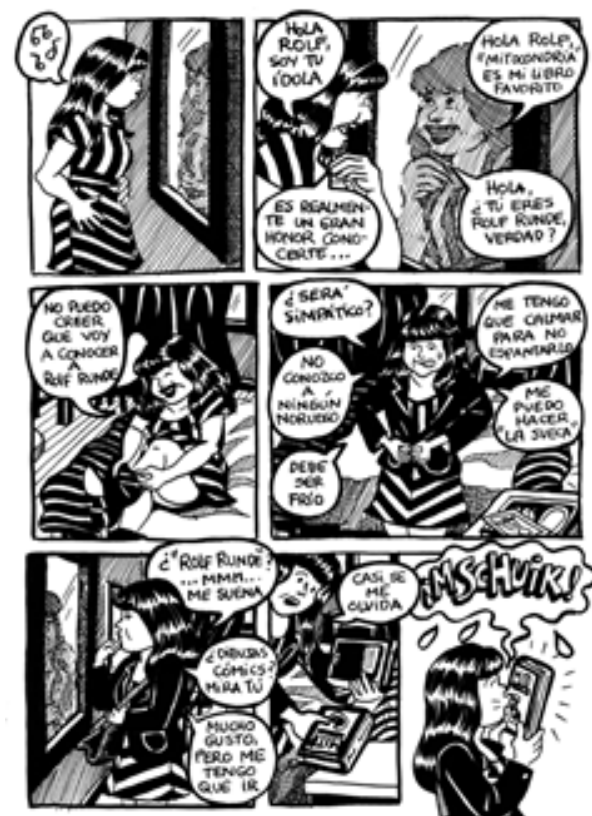

Imagen 2

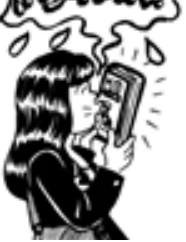

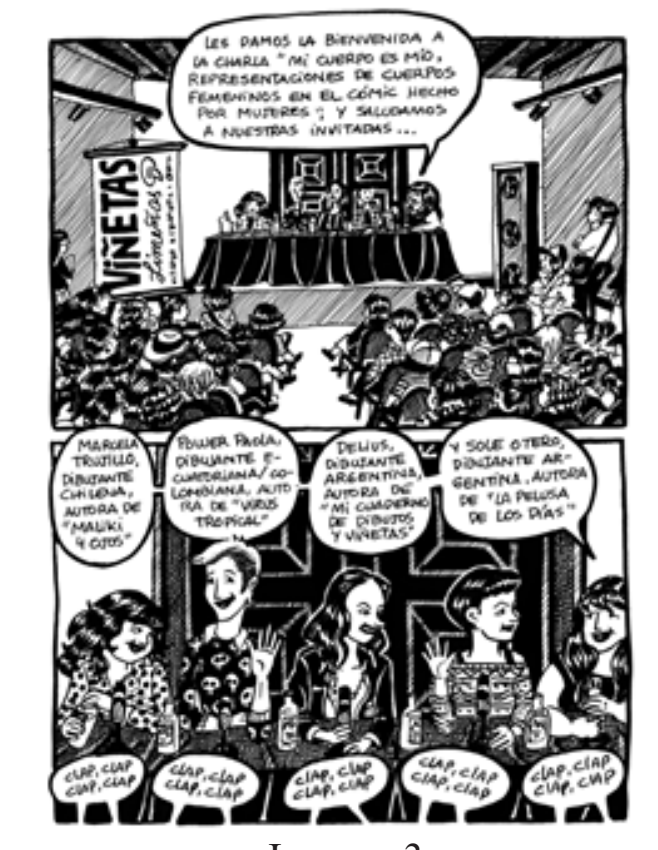

Imagen 3

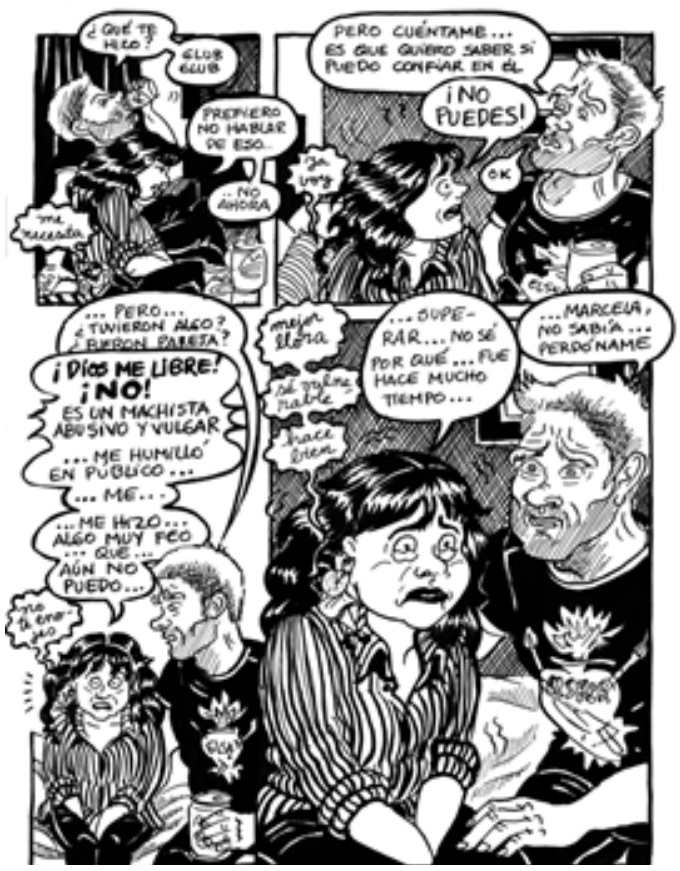

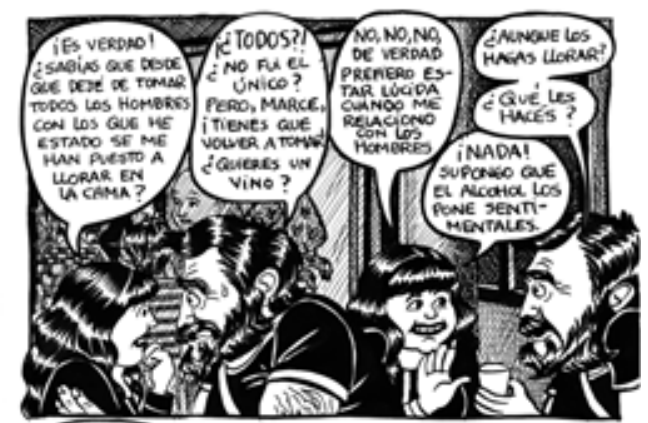

Imagen 4

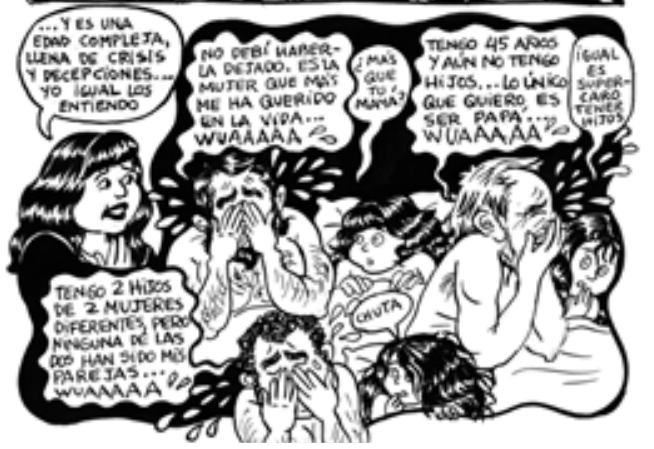

